\title{
Carbon partitioning between shoot organs following early leaf removal
}

\author{
Paolo Sabbatini ${ }^{1, *}$, Dana Acimovic ${ }^{1}$, Tommaso Frioni ${ }^{2}$, Sergio Tombesi ${ }^{2}$, Paolo Sivilotti ${ }^{3}$, Alberto Palliotti ${ }^{4}$ and \\ Stefano Poni $^{2}$ \\ ${ }^{1}$ Department of Horticulture, Michigan State University, East Lansing, MI, USA \\ ${ }^{2}$ Dipartimento di Scienze delle Produzioni Vegetali Sostenibili, Università Cattolica del Sacro Cuore, Piacenza, Italy \\ ${ }^{3}$ Department of Agricultural and Environmental Sciences, University of Udine, Udine, Italy. \\ ${ }^{4}$ Dipartimento di Scienze Agrarie, Alimentari e Ambientali, Università di Perugia, Perugia, Italy
}

\begin{abstract}
In grapevines, basal leaf removal at bloom often induces a reduction of fruit set. The effect is related to a reduction in carbon availability for different plant organs competing for photosynthates. To understand and quantify carbon allocation among major sink organs following the early basal leaf removal, the effect of early basal defoliation was studied in Pinot noir grapevines. The experiment was performed in Michigan, a cool climate viticultural region, and three levels of defoliation were imposed at full bloom: (1) no leaves removed (DF-0); (2) six leaves removed from six basal nodes (DF-6); and (3) ten leaves removed from ten basal nodes (DF-10). A week after the defoliation treatment, ${ }^{13} \mathrm{C}$ pulsing was executed to the defoliated shoots. Photosynthesis $\left(\mathrm{P}_{\mathrm{n}}\right)$, carbon distribution, fruit set, vine performance and basic fruit composition were measured. LR treatments induced higher $\mathrm{P}_{\mathrm{n}}$ when compared to LR- 0 . The highest ${ }^{13} \mathrm{C}$ allocation (\%) was recorded in the shoot apex of the LR-10 treatment and LR-10 had the lowest percentage of ${ }^{13} \mathrm{C}$ transported to the cluster, with a reduced fruit set of about $60 \%$ when compared to LR-0. The severity of leaf removal reduced significantly fruit set and increased shoot apex sink strength at the expense of the cluster.
\end{abstract}

\section{Introduction}

In viticulture, the removal of photosynthetically active leaf area around the cluster zone, early during the growing season (e.g. bloom), is a vineyard management strategy often adopted to reduce vine yield, improve fruit technological maturity and reduce cluster rot complex at harvest $[1,2,3]$. This technique imposes a temporary but drastic source limitation and, when applied around bloom, impact grapevines fruit-set, with a reported reduction between 20 and $50 \%[4,5,6]$. In literature, the reduction of fruit set is often explained by a flower carbon starvation caused by the removal of the photosynthetically efficient portion of the canopy at an early stage of shoot growth [7, 4]. Therefore, the temporary reduction in shoot photosynthates alters carbon assimilation and distribution between vine organs [8]. However, research performed in different viticultural areas on different cultivars have demonstrated that only the removal of $60-80 \%$ of the leaf area-a very large portion of the new vine canopy-can induce a reduction in fruit set. In general, this significant amount of leaf area is the target of manual or mechanical defoliation strategies for crop control of high-yielding cultivars [9] or for cultivars characterized by a tight and compact cluster, prone to rot at harvest $[2,3]$. Pinot noir is a cultivar characterized by a very compact cluster. Humid and wet growing summer condition are always the most important challenge for this early ripening red cultivar for its extreme sensitivity to bunch rot $[3,6]$. A recent three-year study demonstrated that early removal of six basal leaves significantly reduced bunch rot (both botrytis and sour rot) while improving fruit technological maturity via a significant reduction of cluster compactness [6]. Moreover, in several other studies, early basal defoliation has proven to increase sugar, phenolics and anthocyanin concentration and consequently must chemical composition at harvest [9, $10,11,12,13,14]$. The objectives of this work were 1) to evaluate the impact of different levels of shoot basal defoliation applied at bloom on photosynthesis and subsequent carbon allocation to shoot organs and, 2) to evaluate the impact of early defoliation on several physiological parameters, vine performance, fruit set and fruit quality at harvest.

\section{Material and Methods}

\subsection{Plant material and experimental design}

* Corresponding author: sabbatin@msu.edu 
The trial was carried on in 2011 at the Southwest Michigan Research and Extension Center (latitude $40^{\circ} 09^{\prime} \mathrm{N}$, longitude $86^{\circ} 36^{\prime} \mathrm{W}$, elevation $\left.220 \mathrm{~m}\right)$ a research station of Michigan State University, located near Benton Harbor, Michigan. A 10-year-old vineyard of Vitis vinifera L. cv. Pinot noir (clone 777 grafted on $3309 \mathrm{C}$ ), with a spacing of $1.8 \mathrm{~m}$ between vines and 3.0 $\mathrm{m}$ between rows, trained to a vertical shoot positioning system, was used for the experiment. In the winter, vines were pruned to three-node spurs, leaving about 60 buds per vine and during the early stage of the growing season no shoot or cluster thinning was performed. The vines at the time of the treatment application carried 80 clusters and an average of 1.4 clusters per shoot. Shoots were trimmed in the middle of July when their length was about $30 \mathrm{~cm}$ above the last set of the trellis catch wires, positioned at $2.1 \mathrm{~m}$ from the ground. A RCBD (randomized complete block design) was used as the experimental design for the trial. The experiment consisted of one factor, defoliation (DF) of the basal leaves of the growing shoots, at three levels. The levels of defoliation were: no defoliation (DF-0), defoliation of six basal nodes (DF-6) and defoliation of ten basal nodes (LR-10). The experiment consisted of 36 vines, arranged in four blocks and each of the three treatments was randomly assigned to three vines per block. On June $15^{\text {th }}$, when the vines were at full bloom (developmental stage EL-23 as described by 15), the defoliation treatments were applied on shoots carrying about 15 unfolded leaves.

\subsection{Estimation of fruit set and leaf area}

Fruit set (the ratio between the initial number of florets and the number of berries at harvest) was measured on the basal cluster of selected shoots in treatment vines $(n=72)$. Each cluster was photographed in the vineyard at EL-20 (onset of flowering, with 30\% flower cap fallen) and 20 clusters at EL-20 from extra vines adjacent the experimental blocks, photographed against a dark background. The clusters were then transported to the viticulture laboratory of the Department of Horticulture of the Michigan state University and the actual number of flowers was counted. The number of florets in the pictures was counted with Microsoft Office Paint (Windows XP; Microsoft, Redmond, WA, USA) and a linear relationship $\left(\mathrm{y}=2.03 \mathrm{x}, \mathrm{R}^{2}=0.86\right)$ was calculated between the number of florets (y) counted in the laboratory and florets counted on the pictures (x). The basal leaves removed at defoliation time (DF-6 and DF10) were used to measure the leaf area (LA) removed by the treatments. A leaf area meter was used (LI3050AHS, Lambda Instruments Corporation, Nebraska) and, in the vineyard, shoot length was recorded weekly from bud-break to the first canopy trimming, performed the second week of July. During the season, weekly, ten shoots were collected from guard vines and used for calculation of total LA per shoot using a linear relationship between the LA (y) and shoot length (x), described by the equation $\mathrm{y}=17.51 \mathrm{x}-87.52, \mathrm{R}^{2}=0.82$.

\subsection{Yield components and fruit chemistry}

Yield and cluster number per vine, cluster weight and number of berries per cluster were measured at harvest. The data were used to calculate the LA to yield ratio $\left(\mathrm{m}^{2} / \mathrm{kg}\right)$. In the laboratory, basic fruit chemistry and berry color were determined as described by Iland et al. (2004). Approximately $20 \mathrm{~mL}$ of juice from each sample was used for analysis of total soluble solids (TSS) using an Atago PAL-1 Refractometer (Atago USA, Inc.) and $\mathrm{pH}$ (Thermo Scientific Orion $370 \mathrm{pH}$ meter; Beverly, MA, USA). $10 \mathrm{~mL}$ of juice was used for measurement of titratable acidity (TA). The juice was titrated against a standardized $0.1 \mathrm{~N} \mathrm{NaOH}$ solution to a $\mathrm{pH}$ of 8.2 using an automated titrator (Titroline 96; Schott-Geräte, Mainz, Germany) and expressed as $\mathrm{g} / \mathrm{L}$ of tartaric acid equivalents. Anthocyanins and phenolic substances were measured using UV-VIS following Iland et al. 2004. Briefly, one hundred berries were grinded in a tissue homogenizer (Model PT 10/35; Brinkmann Instruments, Luzern, Switzerland) for $1 \mathrm{~min}$. Anthocyanins and phenolic substances were measured by the total phenol assay, using UV-VIS (UV-1800; Shimadzu, Kyoto, Japan) as reported by [16].

\subsection{Photosynthesis Measurements}

Net photosynthesis $\left(\mathrm{P}_{\mathrm{n}}\right)$ and stomatal conductance $\left(\mathrm{g}_{\mathrm{s}}\right)$ were measured with a portable open system gas analyzer (CIRAS-2, PPS Co. Ltd., England) on leaves located on the $11^{\text {th }}$ node of the treatment shoots. The CIRAS-2 was equipped with a $6.25 \mathrm{~cm}^{2}$ leaf chamber; set at ambient relative humidity with an airflow of $350 \mathrm{~mL} / \mathrm{min}$. Photosynthetic measurements were collected at saturating light conditions $(\mathrm{PAR}>1400)$ with a $\mathrm{CO}_{2}$ set at $380 \mathrm{ppm}$. Data were taken between 10:00 and 13:00 hr, 7 days after defoliation and after the shoot photosynthesis was estimated as leaf $\mathrm{P}_{\mathrm{n}} \mathrm{x}$ shoot LA.

\subsection{Carbon Isotope ${ }^{13} \mathrm{C}$ application}

On $22^{\text {nd }}$ of June, three shoots per vine (4 vines per treatment) were enclosed in mylar bags and pulsed for 30 min with ${ }^{13} \mathrm{CO}_{2}$, generated by the reaction of $800 \mathrm{mg}$ of $\mathrm{Ba}^{13} \mathrm{CO}_{2}$ (98 atom \%) with $5 \mathrm{~mL}$ of $85 \%$ lactic acid [17]. Twelve samples per treatment of approximately 3 $\mathrm{cm}^{2}$ from shoot apex, young and mature leaves and clusters were collected 1 hour, 24 hours, 3 and 7 days after ${ }^{13} \mathrm{CO}_{2}$ labeling. Three shoots from non-labeled vines were collected for the measurement of the ${ }^{13} \mathrm{C}$ natural abundance. Shoot components were oven-dried at $70^{\circ} \mathrm{C}$ and dry tissues were grounded and sieved with mesh size 40 . The ${ }^{13} \mathrm{C}$ atom excess $\%$ and the percentage of ${ }^{13} \mathrm{C}$ distribution per shoot component were calculated as reported by [18]. ${ }^{13} \mathrm{C}$ partitioning was determined as difference between pulsed ${ }^{13} \mathrm{C}\left(\mathrm{P}-{ }^{13} \mathrm{C}\right)$ and natural abundance of ${ }^{13} \mathrm{C}\left(\mathrm{N}-{ }^{13} \mathrm{C}\right)$. 


\subsection{Statistical Analysis}

Data were analyzed using one-way ANOVA in PROC MIXED procedure, SAS 9.3 (SAS Institute, Cary, NC, USA) and comparisons between treatments evaluated with the Tukey's HSD test. Regression analysis was performed using SigmaPlot 11 (Systat Software Inc.). Diurnal measurements of $\mathrm{P}_{\mathrm{n}}$ and $\mathrm{g}_{\mathrm{s}}$ and ${ }^{13} \mathrm{C}$ portioning were analyzed using the REPEATED statement function in PROC MIXED and mean separation was evaluated by the t-test.

\section{Results and discussion}

Defoliation reduced leaf area per shoot by $47 \%$ and 86 $\%$ in DF-6 and DF-10 when compared to DF-0 and impacted shoot growth and vine total LA. Main leaf area in DF-6 and DF-10 was $73 \%$ and $34 \%$ when compared to control vines (DF-0), respectively. DF-6 and Df-10 had a leaf area to yield ratio significantly lower than DF$0,-0.27 \mathrm{~m}^{2} / \mathrm{kg}$ and $-0.21 \mathrm{~m}^{2} / \mathrm{kg}$, respectively. DF- 10 reduced fruit set by $60 \%$ and number of berries per cluster $(-24 \%)$ and cluster weight (-65\%), while DF-6, did not affect fruit-set and other cluster parameters (Table 1). The defoliation reduced yield per vine in DF$10(4.1 \mathrm{~kg}$ vs. $9 \mathrm{~kg})$. Sugar accumulation and $\mathrm{pH}$ were found increased in DF-10 vines, while there were no difference between treatments in color concentration (Table 1).

Table 1. Impact of leaf removal on vine and cluster components and fruit chemistry.

\begin{tabular}{|c|c|c|c|}
\hline Treatment $^{1}$ & DF-0 & DF-6 & DF-10 \\
\hline Fruit set (\%) & $26.5 \mathrm{a}$ & $21.6 \mathrm{a}$ & $10.6 \mathrm{~b}$ \\
\hline $\begin{array}{c}\text { Cluster } \\
\text { weight (g) }\end{array}$ & $132 \mathrm{a}$ & $101 \mathrm{~b}$ & $46 \mathrm{c}$ \\
\hline $\begin{array}{c}\text { Yield } \\
\text { (kg/vine) }\end{array}$ & $9.1 \mathrm{a}$ & $9.7 \mathrm{a}$ & $4.1 \mathrm{~b}$ \\
\hline $\begin{array}{c}\text { TSS ( }{ }^{\circ} \text { Brix) } \\
\text { pH }\end{array}$ & $20.9 \mathrm{~b}$ & $21.9 \mathrm{~b}$ & $24.0 \mathrm{a}$ \\
\hline $\begin{array}{c}\text { Titratable } \\
\text { acidity (g/L) }\end{array}$ & $6.09 \mathrm{a}$ & $5.49 \mathrm{ab}$ & $4.95 \mathrm{~b}$ \\
\hline $\begin{array}{c}\text { Anthocyanin } \\
\text { (mg/g) }\end{array}$ & $0.34 \mathrm{a}$ & $0.29 \mathrm{a}$ & $0.37 \mathrm{a}$ \\
\hline $\begin{array}{c}\text { Phenolics } \\
(\mathrm{a} . \mathrm{u} . / \mathrm{g})\end{array}$ & $0.95 \mathrm{~b}$ & $0.86 \mathrm{~b}$ & $1.20 \mathrm{a}$ \\
\hline
\end{tabular}

${ }^{1}$ Means within the column followed by the same letter are not significantly different at $\mathrm{P}<0.05$ by Tukey's HSD test.

DF-0, no leaves removed; DF- 6 , leaves removed from 6 basal nodes; DF-10, leaves removed from 10 basal nodes at bloom.

DF-10 and DF-6 leaf photosynthesis was increased by $42 \%$ and $12 \%$ when compared to DF- 0 , respectively (Table 2). A different result was observed when $P_{n}$ was calculated on a shoot leaf area basis; DF-10 reported a significant decrease on $\mathrm{P}_{\mathrm{n}}$ /shoot, a reduction of about $65 \%$ when compared to the non-defoliated control (Table 2).

Table 2. Impact of early leaf removal on leaf assimilation $\left(\mathrm{P}_{\mathrm{n}}\right)$ and stomatal conductance $\left(\mathrm{g}_{\mathrm{s}}\right)$, at 6 days after full bloom and defoliation.

\begin{tabular}{|c|c|c|c|}
\hline Treatment $^{1}$ & DF-0 & DF-6 & DF-10 \\
\hline $\begin{array}{c}\text { Pn } \\
\left(\mu \mathrm{mol} \mathrm{CO} \mathrm{m}^{-2} \mathrm{~s}^{-1}\right)\end{array}$ & $9.7 \mathrm{~b}$ & $10.9 \mathrm{~b}$ & $13.8 \mathrm{a}$ \\
\hline $\begin{array}{c}\mathrm{Gs} \\
\left(\mathrm{mmol} \mathrm{m} \mathrm{s}^{-1}\right)\end{array}$ & $241.7 \mathrm{~b}$ & $284.2 \mathrm{a}$ & $301.6 \mathrm{a}$ \\
\hline $\begin{array}{c}\mathrm{Pn} / \mathrm{shoot}^{-1} \\
\left(\mu \mathrm{mol} \mathrm{CO} \mathrm{s}^{-1}\right)\end{array}$ & $0.94 \mathrm{a}$ & $0.69 \mathrm{~b}$ & $0.33 \mathrm{c}$ \\
\hline
\end{tabular}

${ }^{1}$ Means within the column followed by the same letter are not significantly different at $\mathrm{P}<0.05$ by Tukey's HSD test.

DF-0, no leaves removed; DF-6, leaves removed from 6 basal nodes; DF-10, leaves removed from 10 basal nodes at bloom.

At the beginning of the pulsing study, the majority of carbon was allocated to the main leaves in all treatments, and no translocation to the clusters was detected (Fig. 1). 24-hours after pulsing, the three treatments had had a fairly even partitioning of ${ }^{13} \mathrm{C}$ in the main leaves and in the growing tips, while a DF-10 reported a significant reduction of the percentage of carbon allocation to the clusters (Figure 1). During the pulsing study, DF-10 allocated significantly less ${ }^{13} \mathrm{C} \%$ in the clusters when compared to other treatments ( $9 \%$ vs $19 \%$ allocated by DF- 0 at 24 hours from the pulsing).

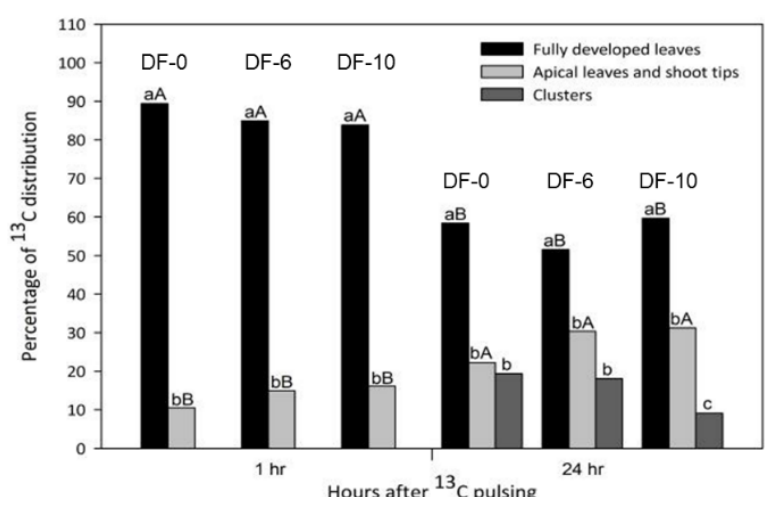

Fig. 1. Percentage of ${ }^{13} \mathrm{C}$ distribution in fully developed leaves, apical shoots and clusters 1 hour and 24 hours after pulsing. Means were based on 4 replicates. The same upper case letters indicate no significant difference within the plant part, $p=0.05$. The same lower case letter indicate no significant difference within the treatment, $\mathrm{p}=0.05$. DF- $0=$ no leaves removed; DF- $6=$ leaves removed from 6 basal nodes; DF-10 $=$ leaves removed from 10 basal nodes at bloom.

Fruit set is a fundamental parameter in determining vine yield, and the physiological process is energy demanding, therefore interacting with several other active sinks in a specific moment of the vine growing 
cycle, when stored reserves are at their minimum level during the season $[19,20,21]$. Young clusters are photosynthetically active, but not self-sufficient and incapable of supporting their growth, with their chlorophyll content decreasing dramatically after bloom $[21,22]$. Therefore, the fruit set process heavily relies upon carbon assimilation of the growing shoots, in particular from the leaves located immediately below or above the cluster $[23,24]$. Inadequate carbon supply to the developing flowers is the reason of reduced fruit-set via embryo abortion and consequent berry drop [19, 25]. Multiple studies have reported that source limitations (e.g. reduction of leaf area by early defoliation) around bloom reduce fruit set, and this physiological process is the basis of viticultural techniques aiming to reduce cluster compactness and the likelihood of fruit rot in cool climate viticultural regions. However, defoliation can induce photosynthetic compensation, potentially reducing the impact on fruit-set (25). In our study, despite the increase in leaf $\mathrm{P}_{\mathrm{n}}$, the effect was not sufficient to compensate the reduction in shoot carbon due to the defoliation (Table 2). Therefore, in DF-10 berry set occurred under conditions of severe carbon starvation, leading to the reduced fruit-set, and consequently a reduced cluster weight and yield per vine (Table 1). These results are consistent with previously published research, where over a 2-year study, defoliation of six to eight basal nodes at full bloom was considered a potential tool able to control fruit-set and cluster compactness in Pinot noir grapevines under cool climate conditions [6]. The reduction in shoot photosynthesis induced by the defoliation treatments was combined with a different carbon partitioning to the major shoot organs; leaves, growing tips and clusters. ${ }^{13} \mathrm{C}$ percentage allocation to the clusters was statistically lower in DF-10, just 24 hours after the pulsing study (Figure 1). Contrarily, the ${ }^{13} \mathrm{C}$ percent allocation to the shoot apex was similar in all the treatments (Figure 1). This result indicates that even under severe sourcelimitation ( $86 \%$ of the leaf area was removed by the DF10 treatment), there was a relative increase of sink strength of shoot apex in DF-10, similar to DF-6 and the control. Grapevine flowers cannot compete with other sinks of the vines, they have a reduced sink-strength, especially in source-limiting conditions, such as an early defoliation [26]. For this reason, fruit set was negatively correlated with ${ }^{13} \mathrm{C}$ allocation to clusters in DF-10. Our results suggest that the shoot apex competition for newly produced carbon is pivotal in controlling the carbon allocated to reproductive organs. In particular, carbon allocation to vegetative organs in condition of severe defoliation is favored at the damage of the reproductive organs. This is confirmed by the fact that DF- 6 treatment had a reduced impact on fruit- set, while DF-10 significantly reduced fruit set (Table 2). Overall, our study demonstrated a dynamic effect of the removal of carbon source via differential carbon allocation to growing sinks. However, the results are suggesting that the significant fruit-set decrease observed in DF-10 is not only related to the amount of carbon assimilated by shoots, as hypothesized in literature [7, 4], but also related to a different allocation strategy induced by the severe defoliation stress.

\section{Conclusions}

The defoliation of large amounts of leaf area at bloom reduced carbon assimilation and affected carbon allocation to the different organs of the shoots. The reduction in carbon assimilation was linearly correlated with the allocation of carbon to the developing shoot apex, a priority in carbon allocation that was also correlated with a strong reduction in fruit set. The dynamic of carbon partitioning after the defoliation was related to the sink strength of the vegetative portion of the growing shoot. This change in hierarchical control of newly produced photoassimilates is pivotal to determine fruit set inconsistencies after early season leaf removal strategies because of carbon portioning, environmental conditions and vine carbohydrates reserve.

\section{References}

1. S. Poni, L. Casalini, F. Bernizzoni, S. Civardi, C. Intrieri, Am J Enol Vitic, 57, 397-407 (2006)

2. B. Hed, H.K. Ngugi, J.W. Travis, Plant Dis, 93, 1195-1201 (2009)

3. P. Sabbatini, G. Howell, HortScience, 45, 18041808 (2010)

4. S. Poni, F. Bernizzoni, S. Civardi, Vitis, 47, 1-6 (2008)

5. L. Tardaguila, J. Blanco, S. Poni, M. Diago, Aust J Grape and Wine R, 18, 344-352 (2012)

6. D. Acimovic, L. Tozzini, A. Green, P. Sivilotti, P. Sabbatini, Aust J Grape Wine R, 22, 399-408 (2016)

7. A. Palliotti, M. Gatti, S. Poni, Am J Enol Vitic, 62, 219-228 (2011)

8. J. Quinlan, R. Weaver, Plant Physiol, 46:527-530 (1970)

9. S. Poni, F. Bernizzoni, G. Briola, A. Cenni, Acta Hortic, 689, 217-226 (2004)

10. S. Poni, F.Bernizzoni, S. Civardi, N. Libelli, Aust J Grape Wine R, 15, 185-193 (2009)

11. S. Lemut, K. Trost,P. Sivilotti, U. Vrhovsek, J Food Comp Anal, 24, 777-784 (2011)

12. Y. Kotseridis, A. Georgiadou, P. Tikos, S. Kallithraka, S. Koundouras, J Agr Food Chem, 60, 6000-6010 (2012)

13. A. Palliotti, T. Gardi, J. Berrios, S. Civardi, S. Poni, Sci Hortic, 145,10-16 (2012)

14. J. Lee, P. Skinkis, Food Chem, 139, 893-901 (2013)

15. D. Lorenz, K. Eichhorn, H. Bleiholder, R. Klose, U. Meier, E. Weber, Aust J Grape Wine R, 1,100-103 (1995)

16. P. Iland, N. Bruer, G. Edwards, S. Weeks, E. Wilkes, Patrick Iland Wine Promotions, (Adelaide, SA, Australia, 2004) 
17. A. Kagawa, A. Sugimoto , K. Yamashita, H. Abe, Plant Cell Environ, 28, 906-915 (2005)

18. K. Morinaga, S. Imai, H. Yakushiji, Y. Koshita, Sci Hortic, 97, 239-253 (2003)

19. B. Coombe, Am J Enol Vitic, 10, 85-100 (1959)

20. M. Candolfi-Vasconcelos, M. Candolfi, W. Koblet, Planta, 192:567-573 (1994)

21. A. Palliotti, A. Cartechini, Am J Enol Vitic, 52:317323 (2001)

22. G. Lebon, O. Brun, C. Magnè, C. Clément. Tree Physiol, 25, 633-639 (2005)

23. C. Hale, Hilgardia, 33:89-131 (1962)

24. Y. Motomura, Am J Enol Vitic, 41:306-312 (1990)

25. M. Candolfi-Vasconcelos, W. Koblet, Vitis, 29,199221 (1990)

26. M. Keller, The Science of Grapevines. (Academic Press, San Diego, USA 2010) 